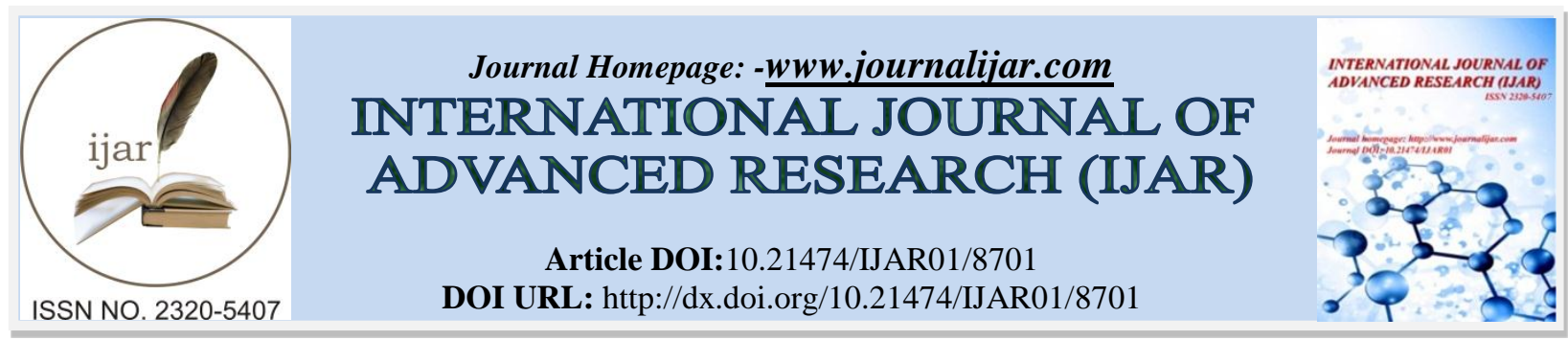

RESEARCH ARTICLE

\title{
COMPARATIVE STUDY TO ASSESS THE EFFECTIVENESS OF OBJECTIVE STRUCTURED CLINICAL EXAMINATION (OSCE) VERSES TRADITIONAL METHOD IN TERMS OF KNOWLEDGE REGARDING ANTENATAL EXAMINATION AMONG B.SC. NURSING $3^{\text {RD }}$ YEAR STUDENTS.
}

Saima Habeeb and Marfa Banoo.

Tutor, Baba Ghulam Shah Badshah University (J \& K).

\section{Manuscript Info}

\section{Manuscript History}

Received: 15 January 2019

Final Accepted: 17 February 2019

Published: March 2019

Key words:-

Effectiveness, OSCE, Traditional practical examination, Antenatal examination.

\section{Abstract}

Background: Most of Nursing Colleges in India follow Traditional Practical Examination for evaluation of practical or clinical skills wherein students are assessed only for knowledge and not for attitude and skill. Traditional methods have several flaws like inter-examiner marks variation, examiners subjectivity, varying difficulty level of different experiments, etc. which prevents uniform marking. These flaws could be minimized by newer methods like OSCE. Objective of the study was to know the effectiveness of objective structured Clinical examination (O.S.C.E) as a formative assessment tool as compared to traditional methods in terms of level of knowledge regarding Antenatal Examination among B.sc nursing students.

Methods: A Non-Experimental research approach with descriptive comparative research design was carried out on 50 Nursing students. Students were subjected to Traditional Practical Examination followed by OSCE. Mean marks for all students were calculated by both the methods. The knowledge questionnaire for Traditional method and different stations for OSCE was used to collect data and rating scale was used for checking the level of satisfaction.

Results: Average marks scored by the students in OSCE (18.74 \pm 4.395$)$ were higher as compared to Traditional Practical Examination $(13.81 \pm 3.814)$ which was statistically significant. $74.4 \%$ of the students strongly agreed that OSCE is fairer in comparison to Traditional Practical Examination. 90.5\% students strongly agreed that variability of examiner \& patient can be removed to a large extent by OSCE.

Conclusion: OSCE was found to be a more effective assessment tool than traditional method. As regards perception, students strongly agreed that OSCE is fairer assessment tool compared to traditional practical examination.

Copy Right, IJAR, 2019,. All rights reserved.

\section{Introduction:-}

An integral part of a Nursing curriculum is an appropriate assessment of the student's clinical/practical competencies. Development of clinical competence in students at all levels is the main aim of Nursing education. The assessment of the students is done through different type of examinations like multiple choice examinations 
(MCQ), short (SAQ) and long answer examination (LAQ). While theory examinations are typically used to assess the knowledge i.e. cognitive domain of students, the purpose of practical examination is to assess the cognitive, psychomotor and affective domain as well. Majority of times the students are assessed only for knowledge. Assessment of attitude and skills is often ignored. It is a well-known fact that the students learn and study the subject for what they will be assessed for i.e. "learning is assessment driven". A single assessment method is not comprehensive in assessing a student. Viva Voce is traditionally used as an assessment tool in practical examinations. It is well known that conventional practical examination has several problems.[1]

Assessments of practical skills in Nursing education are traditionally subjective in nature. Further the subjectivity associated with traditional methods also affects the correlation between marks awarded by different examiners and performance of same candidate negatively.[2] Thus there is a high degree of inter-examiner variation in traditional assessment methods. These need to be changed to objective ones.

An Objective Structured Clinical Examination (OSCE) has been considered as one such method. In some institutions, oral / viva examinations has been replaced by objective structured Practical examination (OSPE) and objective structured clinical examination (OSCE) in Basic Nursing Sciences to overcome the problems which are faced in Traditional Practical Examinations.[3] Historically, it has originated from medical education, and is now being adopted by many disciplines of healthcare education.

Students are given about 5 to 10 minutes at each station and are observed evaluating or are asked questions about a diagnosis or management of a particular condition. Examination is meant mainly for student's interpersonal skills, history taking skills, physical and diagnostic skills. It evaluates student's knowledge base and problem solving ability. Assessment is performed at each station with a predetermined checklist made with the consensus of all examiners. It has demonstrated reliability and validity for assessing clinical performance, though it is labour and time intensive and requires some expertise.[4]

The objective of OSCE is to reduce the chances of examiner bias and assess the students' skills. Though this concept was introduced by Ronald Harden more than thirty five years ago; still it is not implemented in many of Health universities and medical colleges in India.5 Thus, this study is an attempt to evaluate the feasibility of using OSCE as a tool for the formative assessment of undergraduate Nursing students. As OSCE is a new experience for most students and teachers, it is important as educators, that we explore this assessment from the perspective of the participating students and faculties. Considering all this, the study is also aimed to know the satisfaction of students' regarding OSCE.

\section{Material and Methods:}

The research approach adopted for the study was non-experimental with descriptive comparative design. The present study was conducted on fifty students to assess their knowledge and satisfaction regarding type of examination among Nursing students of Baba Ghulam Shah Badshah University, College of Nursing Jammu. The sample was selected using random sampling technique. The tool developed and used for data collection was structured knowledge questionnaire for OSCE and Traditional method and criterion measurement for level of satisfaction. Those students who were not willing to participate were excluded from the study. Thus a total of 50 nursing students were included in the study. Written informed consent was taken from participating students. Trained faculties were involved to prepare the stations for conducting examination with OSCE. A total of 5 stations were finalized. The duration for each station was eight minutes. Checklist was prepared with full participation of the faculties \& it was validated by 2 senior faculties. Thus, OSCE was conducted for a total of 35 marks. Examination was conducted with prior information to the students so that they come well prepared. The confidentiality of the stations was maintained till the end of examination. Volunteers acted as simulated patients during examination. The total marks obtained out of 35marks in Traditional Practical Examination Method were compared with marks obtained in OSPE. Analysis was done using descriptive statistics like frequency \& percentage. Paired t-test was applied to the results which were categorized into TDPE and OSCE, the. The p values obtained were $<0.05$ and hence considered as significant.

\section{Results:-}

The response rate of the students was $100 \%$ as all the students appeared for both the tests. The mean marks scored by the student by traditional method were $13.81 \pm 3.814$ as compared to score in OSCE which was $18.74 \pm 4.395$ (Table 1). This difference of mean scores between the two tests was statistically significant $(\mathrm{p}<0.05)$ Based on the 
response to the questionnaire, students' perception towards OSCE was analysed (Table 2). More than half i.e. 74.4\% of the students strongly agreed OSCE to be fairer in comparison to Traditional Practical Examination. Only $4.7 \%$ students were not sure if OSCE was better than traditional method of examination. 59.3\% students felt that OSCE was easier to pass than Traditional Practical Examination.

Table 1:-Mean marks obtained by students in traditional method of practical examination and OSPE

\begin{tabular}{|l|l|l|l|l|l|}
\hline & Mean & $\begin{array}{l}\text { Standard } \\
\text { deviation }\end{array}$ & $\begin{array}{l}\text { Standard error of } \\
\text { mean }\end{array}$ & T value & P-Value \\
\hline OSPE & 18.74 & 4.395 & 0.553 & 8.7335 & $<0.01 *$ \\
\hline $\begin{array}{l}\text { Traditional } \\
\text { Method }\end{array}$ & 13.81 & 3.814 & 0.480 & & \\
\hline
\end{tabular}

* Significant.

Table 2:-Students satisfaction regarding OSCE $(n=50)$.

\begin{tabular}{|l|l|l|l|l|l|}
\hline Questions & $\begin{array}{l}\text { Strongly } \\
\text { Agree }\end{array}$ & Agree & $\begin{array}{l}\text { Neither Agree nor } \\
\text { disagree }\end{array}$ & Disagree & $\begin{array}{l}\text { Strongly } \\
\text { disagree }\end{array}$ \\
\hline $\begin{array}{l}\text { OSCE is fairer compared with } \\
\text { traditional practical examination. }\end{array}$ & $78.5 \%$ & $19 \%$ & $2.5 \%$ & $0 \%$ & $0 \%$ \\
\hline $\begin{array}{l}\text { OSCE covered a wide range of } \\
\text { knowledge compared with traditional } \\
\text { practical examination. }\end{array}$ & $67 \%$ & $33 \%$ & $0 \%$ & $0 \%$ & $0 \%$ \\
\hline $\begin{array}{l}\text { OSCE is easier to pass and score better } \\
\text { when compared to traditional practical } \\
\text { examination }\end{array}$ & $65 \%$ & $22 \%$ & $13 \%$ & $0 \%$ \\
\hline $\begin{array}{l}\text { OSCE may be exhausting and lengthy if } \\
\text { no. of stations will be increased }\end{array}$ & $5.5 \%$ & $71.5 \%$ & $12 \%$ & $10 \%$ & $1 \%$ \\
\hline Viva - Voce is better than OSPE & $0 \%$ & $10.5 \%$ & $16 \%$ & $39.5 \%$ & $34 \%$ \\
\hline $\begin{array}{l}\text { Examiner bias \& patient variability can } \\
\text { be removed to a large extent by OSCE }\end{array}$ & $90 \%$ & $5 \%$ & $5 \%$ & $0 \%$ & $0 \%$ \\
\hline $\begin{array}{l}\text { Attitude of examiners during OSCE was } \\
\text { better as compared to traditional } \\
\text { practical examination. }\end{array}$ & $53 \%$ & $38 \%$ & $4 \%$ & $5 \%$ & $0 \%$ \\
\hline
\end{tabular}

\section{Implication Of The Study}

1. Nursing Administration: Nurse administrators can make effort to conduct in-service education program based on clinical skills of student nurses. Nurse administrators are in key position to prepare different methods of examination to evaluate knowledge of their nurses.

2. Nursing Education: All nursing students can be taught about OSCE and Traditional method skills. In nursing curriculum these methods must be involved for examination.

3. Nursing Research: Present study generate specific literature for students to check the effectiveness of OSCE vs Traditional method in terms of knowledge regarding antenatal examination.

\section{Recommendations}

1. A similar study can be conducted with a large sample.

2. The study can be conducted in different settings.

3. A comparative study can be conducted with different methods of examination.

4. An experimental study and longitudinal study can also be conducted.

\section{Conclusion:-}

This study concluded that in comparison to Traditional Practical Examination, OSCE was more effective as interexaminer variation and bias were eliminated. Both students and faculties were having a positive approach towards OSCE. Moreover the students were assessed with the same set of questions, thus eliminating any bias in the difficulty level. Thus, OSCE was found to be a more effective assessment tool than traditional method. Use of 
OSCE as formative tool will help in modifying teaching - learning strategies so that both, the teachers as well as the students can derive maximum benefit.

\section{References:-}

1. Wadde SK, Deshpande RH, Pathan MB. Assessment of Students using OSPE/OSCE in Community Medicine: Teachers' and students' Perceptions. FJ Sch J App Med Sci. 2013;1(4):348-53.

2. Ananthakrishnan N. Objective structured clinical / practical examination (OSCE / OSPE). J Postgrad Med. 1993;39(2):82-4.

3. Qureshi GS, Parveen S, Yasmeen T. Objective structured Practical Examination (OSPE): An experience at Dow University of Health Sciences (DUHS) Karachi. Medical Channel. 2012;18(1):5-8.

4. Townsend H, Mcllvenny S, Miller CF, Dunn EV. The use of an objective structured clinical examination (OSCE) for formative and summative assessment in a general practice clinical attachment and its relationship to final medical school examination performance. Medical Education. 2001;35:841-6. 